\title{
A new species of Kiluluma Skrjabin, 1916 (Nematoda: Strongyloidea) from the white rhinoceros, Ceratotherium simum (Burchell) from South Africa
}

\section{Ian Beveridge}

Received: 6 June 2018 / Accepted: 6 August 2018

This article was registered in the Official Register of Zoological Nomenclature (ZooBank) as urn:1sid:zoobank.org:pub:0DF3DA55-449D-4439-8E8A-DC1FD7B1122E. This article was published as an Online First article on the online publication date shown on this page. The article should be cited by using the doi number. This is the Version of Record.

This article is part of the Topical Collection Nematoda.

I. Beveridge ( $)$

Department of Veterinary Biosciences, University of Melbourne, Veterinary Clinical Centre, Werribee, Victoria 3030, Australia e-mail: ibeve@unimelb.edu.au

\begin{abstract}
A new species of Kiluluma Skrjabin, 1916, Kiluluma ornata n. sp., is described from the intestine of the white rhinoceros Ceratotherium simum (Burchell) from South Africa. The new species is virtually identical with a species described as Kiluluma sp., but not named due to a paucity of material then available. The new species most closely resembles $K$. solitaria Thapar, 1924 and K. ceratotherii Beveridge \& Jabbar, 2013, in the possession of an undulating anterior margin of the buccal capsule but differs in the leaf crown elements which have bulbous, lip-like expansions, which are lacking in $K$. solitaria and $K$. ceratotherii.
\end{abstract}

\section{Introduction}

The genus Kiluluma Skrjabin, 1916, currently contains 14 species, comprising 12 species from African rhinoceroses, the black rhinoceros, Diceros bicornis (Linnaeus) and the white 
rhinoceros, Ceratotherium simum (Burchell) (Skrjabin, 1916; Thapar, 1924, 1925; Beveridge \& Jabbar, 2013), with one species (K. vernayi Sandground, 1933) described from the Javan rhinoceros Rhinoceros sondaicus Desmarest by Sandground (1933) and another species $K$. longipene (Molin, 1861) from the South American tapir, Tapir terrestris (Linnaeus) (as $T$. americanus Gmelin) which was redescribed by Travassos (1929).

Beveridge \& Jabbar (2013) described but did not name an additional species from $C$. simum as they only had available a single male and a single female specimen. Additional material similar to this species has subsequently become available and a fuller description of it is presented here.

\section{Materials and methods}

The specimens described herein were obtained from the National Collection of Animal Helminths, ARC - Onderstepoort Veterinary Institute, Pretoria, South Africa (NCAH). Nematodes recovered at autopsy had been preserved in $70 \%$ ethanol. The mid-section of the body was removed from 20 (10 male, 10 female) nematodes for molecular analyses but attempts to extract DNA from the specimens were unsuccessful. The anterior and posterior extremities were cleared in lactophenol for morphological examination. Parts of dissected specimens (oesophagus, spicules) were mounted permanently in Hoyer's medium or (bursa, apical preparation of head) in polyvinyl lactophenol. Two specimens, one male and one female were examined using scanning electron microscopy. They were dehydrated in ethanol and then transferred to hexymethlyldisalazine and allowed to dry before being mounted on stubs. Specimens were not coated and were examined in a Hitachi TM4000 scanning electron microscope. Nematodes cleared in lactophenol were measured using a compound microscope and an ocular micrometer. Drawings were made with a drawing tube. Measurements are presented in millimetres as the range followed by the mean in parentheses. Drawings of apical views of the head are oriented with the dorsal aspect towards the top of the page. In the descriptions of the bursal rays, both the descriptive system of Yorke \& Maplestone (1926) and the numerical system of Chabaud et al. (1970) are used here.

Specimens have been deposited in the Natural History Museum, London, UK (BMNH) and the NCAH. For morphological comparisons, all specimens of Kiluluma in the NCAH were also examined. These included: K. africana Thapar, $1924(10 \hat{\jmath}, 4$ 우, NCAH 1270; K. goodeyi

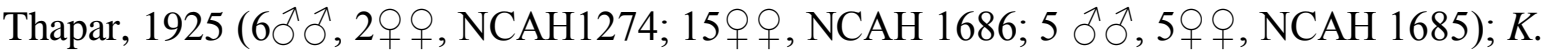

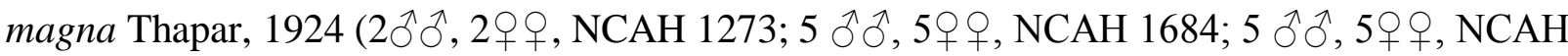


1685; $5 \widehat{\jmath} \widehat{\jmath}, 5 q$ 우, NCAH 2180; 1ㅇ, NCAH 2245); K. pachyderma Thapar, $1924(1 \hat{\jmath}, 3 q$, NCAH 1271); K. rhinocerotis Thapar, 1924 (fragment of one specimen, NCAH 1269) and $K$. solitaria Thapar, 1924 (2q 9 , NCAH 1272).

\section{Kiluluma ornata $\mathbf{n}$. sp.}

Type-host: Ceratotherium simum (Burchell).

Type-locality: Mpumalanga Lowveld $\left(26^{\circ} \mathrm{S}, 30^{\circ} \mathrm{E}\right)$, South Africa.

Site in host: Colon.

Type-specimens: Holotype BMNH 2018.6.6.1; allotype BMNH 2018.6.5.2; paratypes, 3 $\widehat{\jmath}, 3$

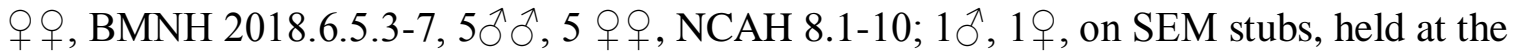
School of Veterinary Science, University of Melbourne.

ZooBank registration: To comply with the regulations set out in article 8.5 of the amended 2012 version of the International Code of Zoological Nomenclature (ICZN, 2012), details of the new species have been submitted to ZooBank. The Life Science Identifier (LSID) for Kiluluma ornata n. sp. is urn:1sid:zoobank.org:act: D353CD2E-F68F-4D54-8B82-A670A30F9A63. Etymology: The species name relates to the ornate array of papillae surrounding the genital cone.

Description (Figs. 1 17)

General. Robust nematodes. Body with prominent widely-spaced annulations; cervical cuticle prominently inflated; cephalic collar prominent; mouth opening surrounded by 6 prominent liplike expansions of anterior surface of leaf crown elements; 2 lateral amphids; 4 submedian bipartite papillae on conical elevations of cuticle; proximal element short, quadrate; distal element longer, ovoid. Internal leaf crown of 6 elements with recurved tips associated with each lip-like cuticular expansion; tips of leaf crown elements not projecting. Buccal capsule thick walled, circular in apical view, prominently lobed anteriorly in dorso-ventral and lateral views. Oesophagus hourglass-shaped without teeth in oesophageal funnel; each lobe of oesophagus with 3 denticles arranged linearly in lumen of oesophagus near anterior extremity. Nerve-ring just anterior to mid-region of oesophagus; deirids and excretory pore posterior to oesophagus. Anterior intestine with c.5 pairs of elongated cells surrounding lumen, followed posteriorly by short ellipsoidal zone of highly pigmented cells, surrounded externally by translucent zone; subsequent region of intestine dilated, becoming narrow then continuing posteriorly as narrow tube. 
Male [Measurements of 10 specimens (types).] Total length 16.018 .0 (16.0); maximum width 0.781 .00 (0.88); buccal capsule 0.1300 .160 (0.145) wide, 0.0500 .070 (0.057) deep; oesophagus $0.420 .53(0.46)$ long; nerve-ring $0.250 .32(0.27)$, excretory pore $0.830 .99(0.90)$ and deirids 0.781 .04 (0.90) from anterior extremity; spicules 1.952 .16 (2.05) long; gubernaculum 0.120 .15 (0.13) long.

Bursa without clear distinctions between ventral, lateral and dorsal lobes; dorsal lobe slightly longer than other lobes; pre-bursal papilla (1) short, stout; ventro-ventral (2) and ventrolateral (3) rays elongate, apposed, not reaching margin of bursa; antero-lateral (4) and mediolateral (5) rays apposed, reaching or almost reaching margin of bursa; postero-lateral ray (6) divergent from other lateral rays, almost reaching margin of bursa; externo-lateral ray (8) arising from lateral trunk, slender, almost reaching margin of bursa; dorsal ray broad at origin, lateral branchlets arising close to origin, slender, each with 2 papillae, one at tip and one proximal to tip, not reaching margin of bursa; main trunk of dorsal ray elongate, swollen anteriorly, dividing near extremity into two elongate branchlets each with single papilla; terminal branchlets reach margin of bursa.

Genital cone with large ventral projection bearing single terminal papilla (0); dorsal lip with paired conical projections (7) each bearing single terminal papilla and elongate, conical structure between them; dorsal lobe of cone surrounded by array of conical projections. Spicules elongate alate; ala arising immediately posterior to capitulum of spicule and extending almost to distal tip of spicule; spicules sinuous, ala arranged spirally around spicule; spicule tips blunt. Gubernaculum not strongly sclerotised, ovoid in dorso-ventral view, curved ventrally in lateral view; wall of posterior region of spicule sheaths from anterior to gubernaculum to cloaca surrounded by strong muscle bundles; cordate thickening at junction of 2 spicule sheaths; entry of sperm duct into cloaca with slightly sclerotised, conical structure; slight sclerotisation surrounds entry of intestine into cloaca.

Female [Measurements of 10 specimens, types.] Length 17.019 .5 (18.0), maximum width 0.901 .10 (0.96); buccal capsule 0.1400 .165 (0.148) wide, 0.0450 .070 (0.058) deep; oesophagus $0.490 .56(0.52)$ long; nerve-ring $0.220 .30(0.26)$, excretory pore $0.830 .98(0.91)$ and deirids $0.831 .00(0.93)$ from anterior extremity; tail short, conical, $0.390 .50(0.44)$ long; vulva immediately anterior to anus, $0.550 .70(0.62)$ from posterior end; phasmids visible in ventral view, immediately anterior to tip of tail; vagina vera 1.251 .60 (1.41) long; sphincters and 
infundibula not differentiable, 1.001 .90 (1.29) long. Eggs ellipsoidal, $0.0700 .090 \times 0.0450 .050$ $(0.080 \times 0.049)$.

\section{Remarks}

The species described here possesses a sinuous anterior margin to its buccal capsule, thereby immediately distinguishing it from all congeners other than $K$. solitaria Thapar, 1924, $K$. ceratotherii Beveridge \& Jabbar, 2013 and Kiluluma sp. described but not named by Beveridge \& Jabbar (2013). The current species differs from both K. solitaria and K. ceratotherii in that the tips of the leaf crown elements are exerted in these species but not in the species described here. The lip-like expansions of the labial cuticle extending anterior to the tips of the leaf crown elements are found only in K. rhinocerotis Thapar, 1924 and possibly in $K$. africana Thapar, 1924, although this is not clearly shown in the relevant illustrations of the latter species and the structures are referred to as 'filiform processes on the inner edges of the lobes' rather than leaf crown elements (Thapar, 1924, p. 216) and are stated to be absent in K. africana (Thapar, 1924, p. 216). The leaf crown elements are similarly not exerted in the unnamed species of Beveridge \& Jabbar (2013).

Differentiation from $K$. rhinocerotis and $K$. africana is complicated when based on measurements as Thapar (1924) gave only a single measurement for organs in each species. However, the female tail length of the current species $(0.39-0.50 \mathrm{~mm})$ distinguishes it from $K$. africana $(0.17 \mathrm{~mm})$, while the length of the vagina vera $(1.25-1.60 \mathrm{~mm})$ distinguishes it from $K$. rhinocerotis $(0.87 \mathrm{~mm})$. The key features differentiating the species described here from $K$. rhinocerotis and $K$. africana are the lobed anterior extremity of the buccal capsule and accessory appendages of the genital cone. Unfortunately, these features were not observable in the typespecimens of the respective species (Beveridge \& Jabbar, 2013). They were confirmed by examination of additional specimens of $K$. africana (NCAH 1270) but not for K. rhinocerotis, for which the single specimen in NCAH (1269) was in a poor state of preservation. However, in the illustrations of $K$. rhinocerotis (figure 2 in Thapar, 1924) the buccal capsule is clearly depicted as having a non-lobed anterior margin, therefore discriminating it from the species described here. In the dorsal ray of the species described here, the anterior branchlets do not reach the margin of the bursa (Figs. 12, 14), which differentiates the species from $K$. rhinocerotis (see figure 37 in Beveridge \& Jabbar, 2013) but not $K$. africana (see figure 40 of Beveridge \& Jabbar, 2013). The current species is therefore closest to Kiluluma sp. of Beveridge \& Jabbar (2013). There are minor differences between the two in that the anterior branchlets of the dorsal ray are more slender as are the externo-dorsal rays (rays 8) and the female tail has a different 
shape in the species described here. In addition, the oesophageal denticles are closer to the anterior end of the oesophagus (Fig. 7) and the oesophagus is shorter relative to its width (Fig. 2). The significance of these differences is not clear and lacking molecular data for the current species, it is described based on morphological features with the hope that future molecular studies will support its independence.

\section{Discussion}

The inadequacy of descriptions of species Kiluluma from rhinoceroses expressed by Taylor (1925) were repeated more recently by Knapp et al. (1977) who suggested that a combined morphological and molecular approach would be needed to confirm the validity of species currently allocated to the genus. Subsequently, Beveridge \& Jabbar (2013) redescribed $K$. solitaria together with DNA sequence data from captive rhinoceroses in Australia, described a new species from $C$. simum which they named $K$. ceratotherii, with DNA sequence data, again from captive $C$. simum and identified a second new species, with sequence data, but which they did not name due to the lack of adequate specimens. The species described here appears to be identical with the un-named species of Beveridge \& Jabbar (2013), but attempts to extract DNA from 20 specimens of the new species were unsuccessful. There are relatively minor differences between the descriptions of the two series of specimens, but overall they are extremely similar and are here suggested as representing the same species pending the more detailed examination of nematodes from rhinoceroses.

A major obstacle in the study of this genus is the poor state of preservation of the typespecimens of Kiluluma spp. in BMNH. As a consequence, all additional material in South African collections (NCAH) was also examined, including the collection reported by Mönnig (1927), although these specimens also were not well preserved. In spite of these difficulties, it was decided to erect a new species with the expectation that additional collecting would clarify existing uncertainties.

The present description provides additional information of several anatomical features of the genus which may, in the future, prove to be of taxonomic significance.

The description of the anterior intestine of the species of Kiluluma described here suggests that it is highly specialised with a short anterior region surrounded by elongated cells then a short, darkly-pigmented region surrounded by a translucent coat and then a dilated region leading into a narrow intestine continuing to the anal region. This specialisation of the anterior region of the intestine has not been reported previously, but was seen is several other members 
of the genus represented in NCAH collections and may be a feature of the genus. Additional studies are needed to verify this suggestion.

Beveridge \& Jabbar (2013) commented that the peri-cloacal structures of Kiluluma spp. were poorly understood and that the interpretations of Thapar (1925) required re-examination. In the current species, a prominent though poorly sclerotised gubernaculum is present which is oval in dorso-ventral views, with or without a posterior indentation (Figs. 11, 15) and is curved ventrally in lateral views (Fig. 16). The region of the gubernaculum is surrounded by hypertrophied muscular structures (Fig. 16). In this species, additional sclerotised structures are present at the entry of the ejaculatory duct and the intestine into the cloaca (Fig. 16) and there is a pair of bilobed structured at the junction of the spicule sheaths anterior to the gubernaculum (Fig. 11). The sclerotised structure at the entry of the ejaculatory duct into the cloaca was illustrated in K. ceratotherii by Beveridge \& Jabbar (2013; figure 21) and in Kiluluma sp. of Beveridge \& Jabbar (2013; figure 36) but its relationship with the ejaculatory duct was not apparent in those specimens. Beveridge (1987) described paired lateral thickenings and a cordate central thickening of the spicule sheaths as being a uniform character within the Chabertiidae and therefore potentially of taxonomic significance. However, comparable anatomical arrangements within the Strongylidae are poorly understood. The current species appears to have paired thickening at the junction of the spicule sheaths, but the detailed anatomical arrangements of these structures requires further study.

The addition of yet another new species to the genus Kiluluma suggests that the full diversity of this genus remains to be determined, and again underlines the importance of confirming the validity of the existing species with more detailed descriptions and supplementary molecular data as suggested by Knapp et al. (1977), a process which may be difficult since the host species of this genus are either threatened or endangered, thus limiting the possibility of making more extensive collections.

Acknowledgements Thanks are due to Dr K. Junker, National Collection of Animal Helminths, ARC - Onderstepoort Veterinary Institute, Pretoria, South Africa for providing the specimens for study and to Eileen Harris (BMNH) for access to their collections and for accessioning the new material.

\section{Compliance with ethical standards}


Conflict of interest The author declares that he has no conflict of interest.

Ethical approval All applicable institutional, national and international guidelines for the care and use of animals were followed.

\section{References}

Beveridge, I. (1987). The systematic status of Australian Strongyloidea (Nematoda). Bulletin du Muséum National d'Histoire Naturelle, Paris, Série 4, 9, 107126.

Beveridge, I., \& Jabbar, A. (2013). New species of Kiluluma Skrjabin, 1926 (Nematoda: Strongylida) from the white rhinoceros Ceratotherium simium (Burchell), with a redescription of K. solitaria Thapar, 1924. Systematic Parasitology, 85, 131145.

Chabaud, A. G., Puylaert, F., Bain, O., Petter, A. J., \& Durette-Desset, M-C. (1970). Remarques sur l'homologie entre les papilles cloacales des Rhabditides et les côtes dorsales des Strongylida. Comptes Rendus Hebdomadaire des Séances de l'Académie des Sciences, $271,17711774$.

Knapp, S. E., Krecek, R. C., Horak, I. G., \& Penzhorn, B. L. (1997). Helminths and arthropods of black and white rhinoceroses in southern Africa. Journal of Wildlife Diseases, 33, 492502.

Mönnig, H. O. (1927). Helminthological notes. $11^{\text {th }}$ and $12^{\text {th }}$ Report of the Director of Veterinary Education and Research. Pretoria: Department of Agriculture, Union of South Africa, pp 221226.

Sandground, J. H. (1933). Two new helminths from Rhinoceros sondaicus. Journal of Parasitology, 19, 192204.

Skrjabin, K. I. (1916). Parasitic trematodes and nematodes collected by the expedition of Prof. V. Dogiel and I. Sokolov in British East Africa. Scientific Reports of the zoological expedition to British East Africa and Uganda by Prof. V. Dogiel and I. Sokolov in 1914, l(4), 1157.

Taylor, E. L. (1925). The genus Kiluluma. Annals of Tropical Medicine and Parasitology, 19, 5355.

Thapar, G. S. (1924). On Kiluluma Skriabin, a genus of strongylid nematodes parasitic in the African rhinoceros. Journal of Helminthology, 2, 209-238.

Thapar, G. S. (1925). On some new members of the genus Kiluluma from the African rhinoceros. Journal of Helminthology, 3, 6380. 
Travassos, L. (1929). Contribuição ao conhecimento dos Strongyloidea parasitos do Tapirus americanus. Memórias do Instituto Oswaldo Cruz, 22, 135144.

Yorke, W., \& Maplestone, P. A. (1926). The nematode parasites of vertebrates. London: Churchill \& Sons, 536 pp.

\section{Captions to figures}

Figs. 1-10 Kiluluma ornata n. sp. ex Ceratotherium simum (Burchell). 1, Anterior region of male, left lateral view, showing different regions of anterior intestine; 2, Anterior extremity, left, lateral view; 3, Cephalic region, ventral view; 4, Cephalic region, right lateral view; 5, Cephalic extremity, apical view; 6, Cephalic papilla, lateral view; 7, Anterior region of oesophagus showing denticles in lining; 8, Female tail, right lateral view; 9, Female tail, ventral view showing phasmids; 10, Vagina and ovejector, lateral view. Scale-bars: 1-5, 7-10, $0.1 \mathrm{~mm}$; , $0.01 \mathrm{~mm}$

Figs. 11-16 Kiluluma ornata n. sp. ex Ceratotherium simum (Burchell). 11, Spicules, ventral view; 12, Bursa, apical view; 13, Bursa, lateral view; 14, Bursa, dorsal view; 15, Gubernaculum, ventral view; 16, Cloacal region, right lateral view. Numerals on Figs. 12 and 13 represent the numbering system for the bursal rays of Chabaud et al. (1970). Abbreviations: e, ejaculatory duct; g, gubernaculum; I, intestine. Scale-bars: 11-14, 16, $0.1 \mathrm{~mm} ; 15,0.01 \mathrm{~mm}$

Fig. 17 Scanning electron micrograph of the internal surface of the bursa of Kiluluma ornata $\mathrm{n}$. sp. ex Ceratotherium simum (Burchell). Legend: C, cloaca; numerals, terminations of rays 4-6 and papillae of genital cone, 0,7 . Scale-bar: $0.1 \mathrm{~mm}$ 


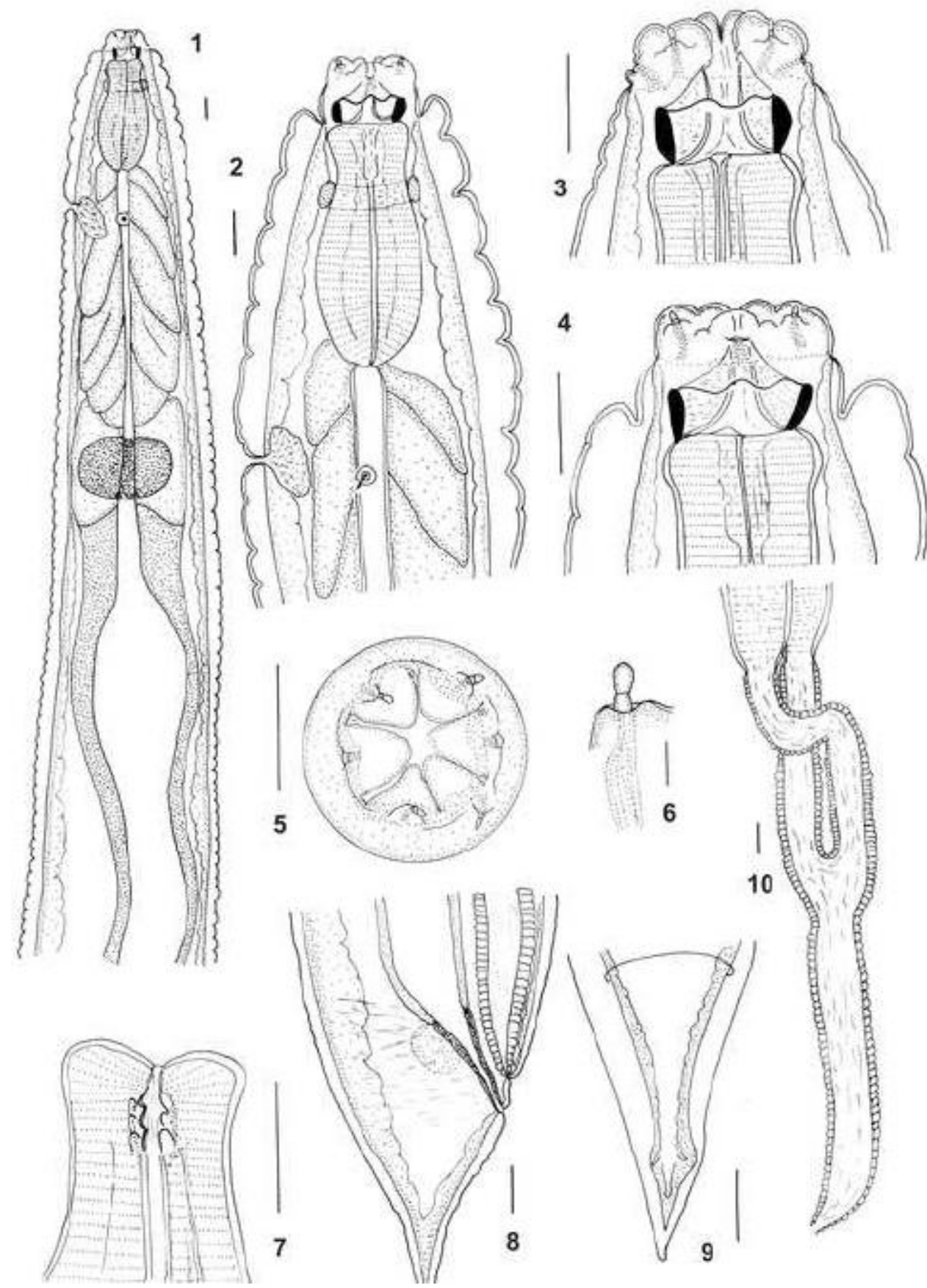




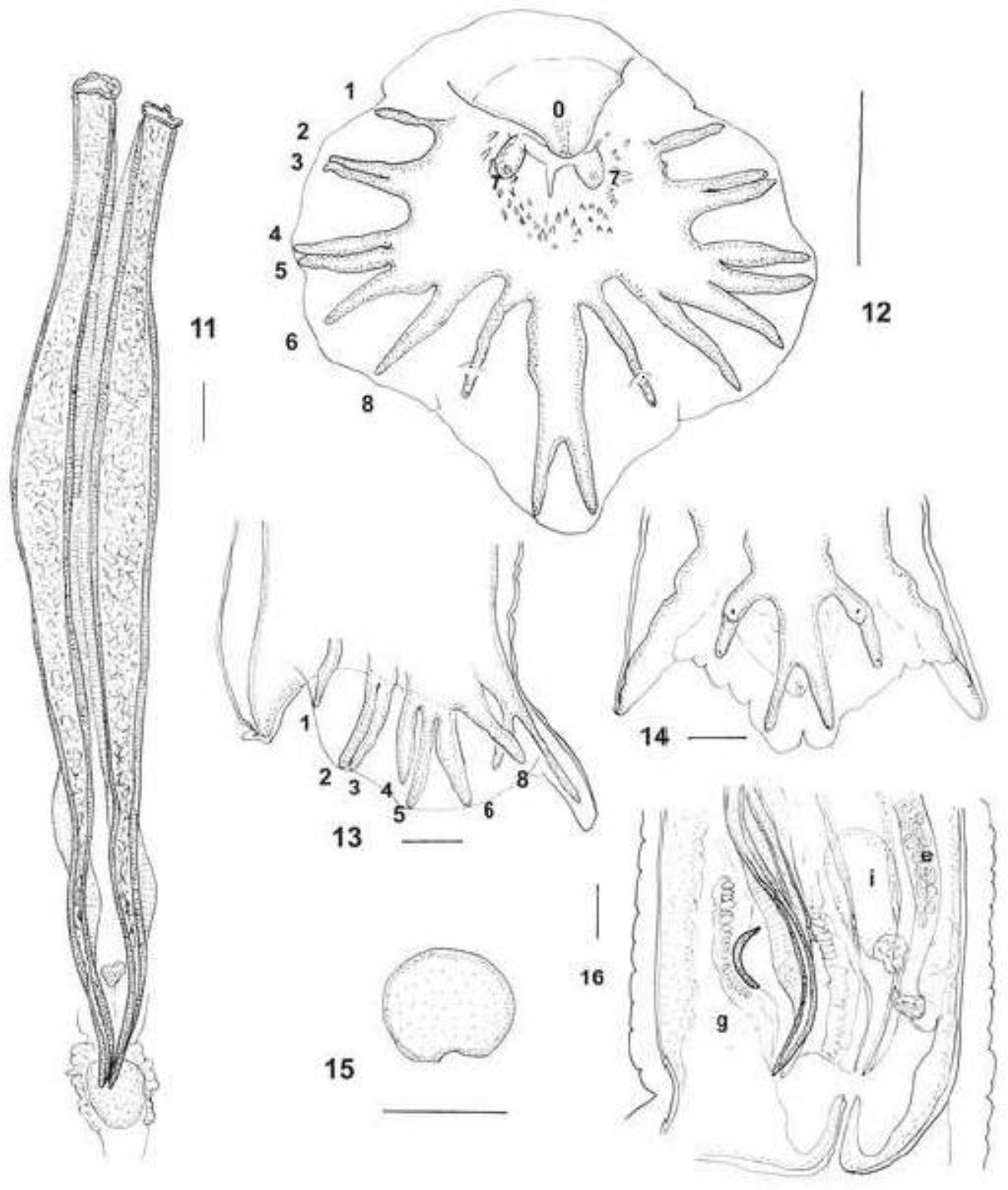




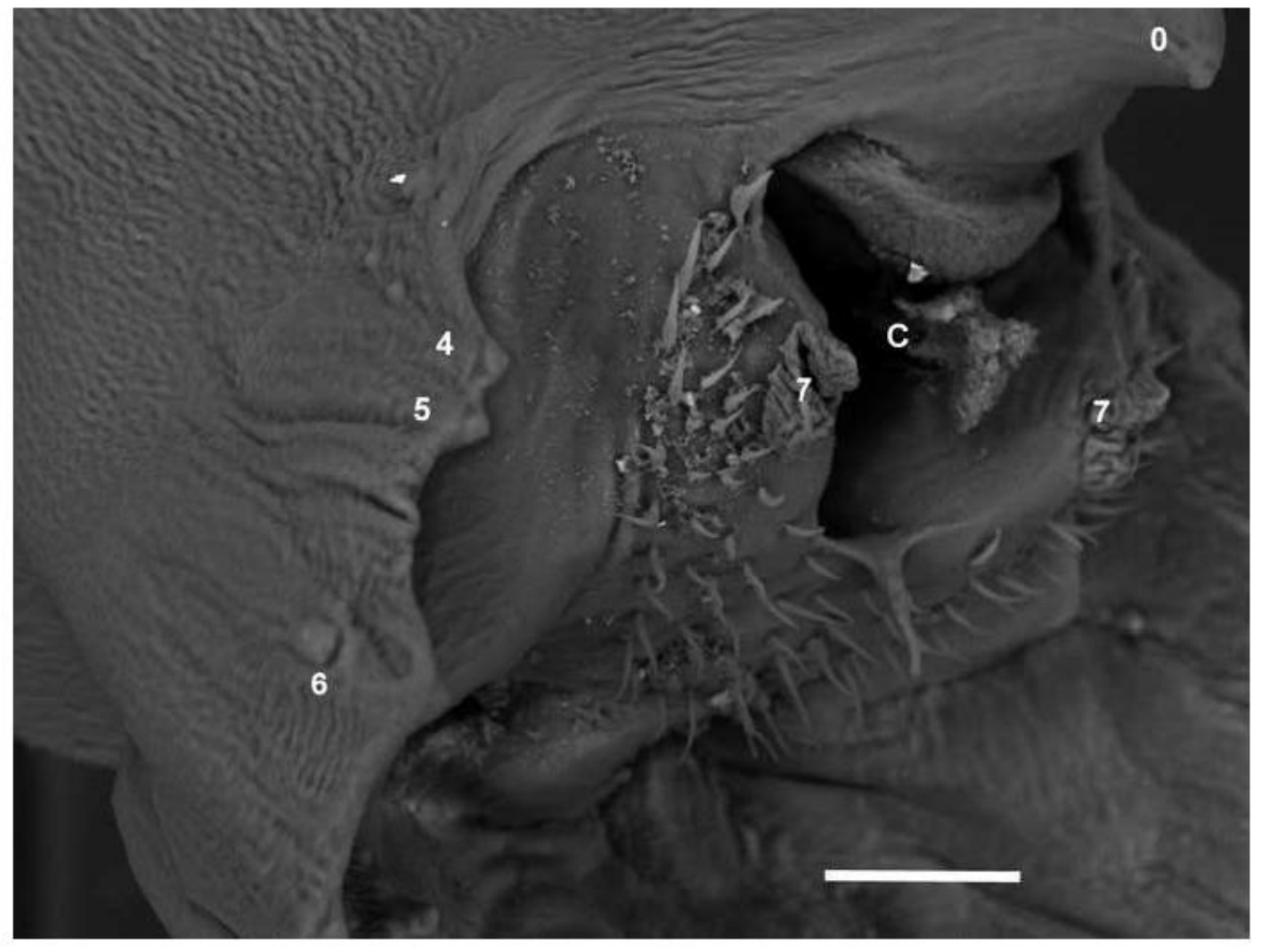




\section{University Library}

\section{- M M N E R VA A gateway to Melbourne's research publications}

Minerva Access is the Institutional Repository of The University of Melbourne

Author/s:

Beveridge, I

Title:

A new species of Kiluluma Skrjabin, 1916 (Nematoda: Strongyloidea) from the white rhinoceros, Ceratotherium simum (Burchell) from South Africa

Date:

2018-11-01

Citation:

Beveridge, I. (2018). A new species of Kiluluma Skrjabin, 1916 (Nematoda: Strongyloidea) from the white rhinoceros, Ceratotherium simum (Burchell) from South Africa. SYSTEMATIC PARASITOLOGY, 95 (8-9), pp.841-847. https://doi.org/10.1007/s11230-018-9812-2.

Persistent Link:

http://hdl.handle.net/11343/283300 